\title{
A formação do professor em Filosofia no Brasil: restrição de pensamento e testemunho
}

\section{Tiago Brentam Perencin ${ }^{1}$}

\section{Resumo}

Ambiciono analisar no presente artigo como a ausência histórica da produção de pensamento sobre a formação docente se faz sentir na tradição universitária filosófica na contemporaneidade brasileira. Parto da hipótese de que a restrição histórica do debate sobre o ensino de filosofia no Brasil acarretou a ausência de um campo dedicado a refletir sobre a formação docente na atualidade. Argumentarei a partir de dois caminhos complementares: (1) De minhas pesquisas envolvendo o ensino de filosofia nos periódicos de filosofia e de educação em circulação no início da criação da Universidade brasileira e (2) de meu testemunho de formação como estudante e como professor de filosofia no país.

Palavras-chave: Formação Docente em Filosofia no Brasil; Ensino de Filosofia no Brasil; Periódicos Brasileiros.

\section{Résumé}

J'ai l'ambition d'analyser dans cet article comment l'absence historique de la production de la pensée sur la formation du professeur se fait sentir dans la tradition universitaire philosophique dans la contemporanéité brésilienne. Je pars de l'hypothèse que la restriction historique du débat sur l'enseignement de la philosophie au Brésil a entrainé l'absence d'un champ dédié à la réflexion sur la formation du professeur dans l'actualité. J'argumenterai à partir de deux raisonnements complémentaires : (1) mes recherches relatives à l'enseignement de la philosophie dans les revues de philosophie et de l'éducation en circulation au début de la création de l'Université brésilienne et (2) mon témoignage de formation en tant qu'étudiant et professeur de philosophie dans ce pays.

Mots-clés: Formation du Professeur de Philosophie au Brésil; Enseignement de la Philosophie au Brésil; Revues Brésiliennes.

${ }^{1}$ Licenciado (2012) e Bacharel (2014) em Filosofia pela Universidade Estadual Paulista (UNESP), Campus de Marília, mestre (2015) e doutorando em Filosofia e História da Educação no Brasil, pelo Programa de Pós-Graduação em Educação da UNESP/Marília.

Filosofia e Educação [RFE] - Volume 9, Número 2 - Campinas, SP Junho-Setembro de 2017 - ISSN 1984-9605 - p. 23-47 


\section{Considerações iniciais}

mbiciono apresentar neste artigo algumas considerações sobre a 1 formação do professor em filosofia no Brasil tomando dois experiência como egresso em um curso de filosofia, que vivenciou a situação de descaso por parte do Departamento de Filosofia em face da produção de pensamento sobre a docência, quanto a divulgação de parte dos resultados obtidos em outras de minhas pesquisas já concluídas (PERENCINI e GELAMO 2011; PERENCINI 2013, 2015). Tais investigações acadêmicas só foram possíveis a partir de meu percurso enquanto estudante de filosofia que, devido aos acontecimentos existenciais, fui me tornando professor de filosofia e percebendo uma série de dissonâncias interiores às práticas de formação universitária, sobretudo quando direcionadas ao âmbito escolar.

Nessa perspectiva, a problemática que ora analisarei pode ser descrita a partir da seguinte enunciação: Como a ausência histórica da produção de pensamento sobre a formação docente se faz sentir na tradição universitária filosófica na contemporaneidade brasileira? A hipótese trazida é de que a ausência histórica de produção de pensamento sobre o ensino de filosofia no país promove a pouca visibilidade ao campo da formação docente por parte da área acadêmica em filosofia na atualidade.

O objetivo geral deste artigo é mostrar detalhadamente como ocorreu e como ocorre essa restrição. Entendo, evidentemente, que os eixos de "formação do professor" e "ensino de filosofia" são temários diferentes e trazem cada um a sua maneira determinadas especificidades, mas procurei movimentar o eixo da formação docente para o das práticas sobre o ensino de filosofia justamente porque as minhas pesquisas sugeriram a inexistência de um campo de pensamento sobre a formação docente em específico.

No propósito de mostrar justamente esta aridez, argumentarei levando em consideração os resultados de minhas pesquisas já concluídas sobre a produção bibliográfica do ensino de filosofia no Brasil nos anos iniciais de constituição da academia brasileira, que fizeram parte de meu percurso

Filosofia e Educação [RFE] - Volume 9, Número 2 - Campinas, SP Junho-Setembro de 2017 - ISSN 1984-9605 - p. 23-47 
formativo até o momento, bem como trazendo a minha subjetividade como marca de quem vivenciou contemporaneamente a questão. Muito embora uma concepção tradicional de investigação acadêmica degenere o relato e a subjetividade como parte de um resultado de pesquisa, entendo que a constatação da ausência de reflexão filosófica acerca da formação docente em filosofia por parte de minha experiência singular como egresso de um curso universitário considerado clássico no país é um testemunho comum entre outros tantos estudantes e por isso merece a devida visibilidade.

Jeanne Marie Gagnebin, em seu artigo Memória, História, Testemunho, lembra-nos que a testemunha é aquele que escuta uma narrativa da experiência do outro. No caso da autora, já que se referida aos sobreviventes dos campos de concentração, escuta uma narrativa da experiência inenarrável do horror, e como tal se torna o avesso da indiferença. Ela propõe uma necessária ampliação do conceito de testemunha, que gostaria de tomar nota como ofício no presente artigo:

Testemunha não seria somente aquele que viu com seus próprios olhos, o bistor de Heródoto, a testemunha direta. Testemunha também seria aquele que não vai embora, que consegue ouvir a narração insuportável do outro e que aceita que suas palavras levem adiante, como num revezamento, a história do outro: não por culpabilidade ou por compaixão, mas porque somente a transmissão simbólica, assumida apesar e por causa do sofrimento indizível, somente essa retomada reflexiva do passado pode nos ajudar a não repeti-lo infinitamente, mas a ousar esboçar uma outra história, a inventar o presente" (2006, p. 57).

Considero que, na condição de estudante, professor e pesquisador dedicado a pensar a formação docente em filosofa na atualidade brasileira, tenho exercitado justamente esse papel de testemunha porque ambiciono praticar "essa retomada reflexiva do passado", calcada pela tradição universitária que me formou, no propósito de "não repeti-la infinitamente". Sinto uma experiência de esgotamento em face das práticas de formação em 
filosofia por parte minha geração na atualidade, tarefa que exige "esboçar uma outra história, a inventar o presente". É justamente a partir desse lugar de fala como estudante, mas também como professor e pesquisador em construção, que pretendo contribuir para o presente dossiê.

\section{Testemunho de formação em Filosofia}

Suponho que não seja possível abarcar exatamente o início e o fim de uma experiência, mas o curso do esquecimento não me rouba a lembrança viva de como a minha fratura formativa como estudante e como professor de filosofia se potencializou. Iniciei a graduação em Filosofia na Universidade Estadual Paulista "Julio de Mesquita Filho" (UNESP), Faculdade de Filosofia e Ciências de Marília-SP, no ano de 2008 e já no ano seguinte assumi a posição de professor de filosofia no Cursinho Alternativo da Unesp de Marília $(\mathrm{CAUM})^{2}$. Ainda iniciante na graduação, o meu ofício docente balizou-se em duas esferas. Tanto na projeção de certos docentes na Universidade, que tomava como espelho, quanto na recorrência aos manuais tradicionais de filosofia para o ensino médio, que vigoravam no Brasil à época.

Os docentes em que, de alguma forma, poderia me espelhar tratavam de explicar os textos e os rígidos conceitos de determinados autores da tradição filosófica, ao passo que os manuais ofereciam um modo de ensino calcado entre temas e a história da filosofia. O meu ofício docente foi ganhando forma nesse intento: instruir estudantes de um grau inferior ao universitário na história e nos temas da tradição filosófica. Para um iniciante, não parecia desagradável a tarefa, sobretudo porque anos depois percebi que era exatamente essa a especificidade de minha formação universitária em filosofia.

\footnotetext{
${ }^{2}$ Referência ao Projeto de Extensão "Cursinho Alternativo da Unesp de Marília” (CAUM), coordenado pelo Prof. Dr. Luiz Roberto Vasconcellos Boselli. Tendo iniciado as suas atividades em 1998, atualmente o projeto conta com 120 estudantes ingressos por ano. Além de complementar a formação do aluno/a adquirida em nível de ensino médio, possibilita também ao graduando uma melhor formação atinente ao ensino e à pesquisa. Todas as informações sobre o CAUM encontram-se no endereço: http://www.marilia.unesp.br/index.php?inputNoticiasBuscaTopo=Caum\#!/caum.
} 
Basta um recuo a dois importantes documentos para averiguar essa finalidade de formação. O primeiro é local. No Projeto Pedagógico da UnespMarília (s/d, p. 1), explicita-se a especificidade do licenciado da seguinte maneira:

Igualmente familiarizado com a técnica da 'explicação de texto', tornando-a privilegiado instrumento do ensino da Filosofia no $2^{\circ}$ grau, o licenciado deverá, também, promover o contato produtivo de seus alunos com os mais significativos movimentos da cultura ocidental, no domínio das ciências e das artes ${ }^{3}$.

Portanto, a instrução na tradição para o ensino da filosofia no nível médio deveria contar com a "explicação de texto", privilegiado instrumento para a formação do professor.

O outro documento é de relevância nacional, mas cumpre o mesmo propósito. As Diretrizes curriculares para os cursos de graduação em filosofia no Brasil (BRASIL, 2001, p. 3) ${ }^{4}$ unem o perfil formador, modalidade de bacharel e licenciado, à:

Sólida formação de história da filosofia, que capacite para a compreensão e a transmissão dos principais temas, problemas, sistemas filosóficos, assim como para a análise e reflexão crítica da realidade social em que se insere ${ }^{5}$.

\footnotetext{
${ }^{3}$ Esse projeto não dispõe de número de páginas, mas pode ser encontrado no seguinte endereço: http://www.marilia.unesp.br/Home/Graduacao/Filosofia/projeto.pdf. Acesso em: 10 janeiro 2015.

${ }^{4}$ Essas diretrizes podem ser encontradas em: http://portal.mec.gov.br/cne/arquivos/pdf/CES0492.pdf. Acesso em: 10 de Janeiro 2015.

${ }^{5} \mathrm{O}$ modelo de curso que vai ao encontro desse modo de ensino é o de graduação da Universidade de São Paulo. O Projeto Pedagógico do curso demarca muito bem o modo de compreensão do ensino de filosofia, a partir do rigor na leitura do texto e no trato histórico em suas questões, oferecido em cursos monográficos: "Se observarmos que o lema, talvez mais fundamental, que presidiu as orientações pedagógicas e da pesquisa na formação do Departamento de Filosofia foi, certamente, o de que 'o ensino da filosofia deverá ser primeiramente histórico' para ser, em seguida, 'mais contemporâneo', e o de que tal ensino se faz pela leitura rigorosa, frequentação e meditação dos textos dos grandes filósofos, compreenderemos que o ensino que oferecemos tenha se organizado segundo o eixo da 'História da Filosofia' e se pautado por cursos 'monográficos' de interpretação dos clássicos em suas grandes obras" (s/d, s/p).
}

Filosofia e Educação [RFE] - Volume 9, Número 2 - Campinas, SP Junho-Setembro de 2017 - ISSN 1984-9605 - p. 23-47 
À "técnica de explicação de texto" soma-se a "sólida formação em história da filosofia", recebidas na graduação, como os dois privilegiados instrumentos que deveriam reger o perfil do licenciado na educação média.

Recordo que a minha grande motivação à época era aprimorar tais conteúdos e, sobretudo, formar-me a partir dos melhores métodos de exegese e transmissão do texto, podendo, assim, ensinar a filosofia a todos. Somada às atividades de professor, iniciei uma pesquisa sobre retórica, esperando apurar os modos de instruir estudantes na tradição filosófica. Fiel à (in) formação recebida, dediquei-me à centralidade da História da Filosofia a partir da sua transmissão e da explicitação de seus textos. A finalidade desse ensino era persuadir o outro de que tais conteúdos eram importantes e precisavam ser estudados. A sala de aula existia para mim como uma grande contenda para os exercícios retóricos a que a pesquisa me aliciava. Sobre a exigência dos conceitos abarcados pelos textos filosóficos, acreditava que o fortalecimento didático sanaria quaisquer dificuldades em seu ensino.

Nisso, a minha formação como professor de filosofia estaria plenamente realizada: "explicar textos", em sua maioria rebuscados, a estudantes que, diferentemente de mim, não escolheram a filosofia como formação, utilizando-me de uma "história da filosofia" cronológica e evolutiva como o seu instrumento privilegiado. Exatamente assim ocorriam as minhas aulas na universidade. Era para essa finalidade que eu, estudante de filosofia, estava sendo formado.

Pois bem. Na contramão disso, à medida que eu me aprofundava na graduação - e particularmente no ofício de professor - atentei-me para uma série de dissonâncias. Mostro três delas. Primeiro, os cursos arrogados de "História da Filosofia" ocupavam a centralidade do rol de disciplinas tanto no bacharelado, como na licenciatura. Mas eram monográficos, o que pouco permitia a nomeação "História". Segundo, os cursos nomeadamente temáticos (ética, política, estética, etc.), por sua vez, ora eram igualmente monográficos, ora meramente narrativos, sobre autores e seus sistemas de pensamento, com proximidade ao tema referido. E, por fim, nenhuma "História da Filosofia" 
sequer tencionou quaisquer reflexões acerca das questões conceituais, teóricas e metodológicas em história ${ }^{6}$. Algo parecia rachado no processo.

Retomando a prática de professor, que explicava textos à luz da história da filosofia, confesso que a minha teoria foi, definitiva e catastroficamente, outra. Não demorei a perceber a restrição da estratégia para qual estava sendo formado na licenciatura. O conteúdo da história da filosofia e as técnicas didáticas para a explicação de texto eram insuficientes. A sala de aula não servia mais como o palco para as minhas repetidas performances oratórias. Tornou-se mesmo um lugar desconfortável, arenoso e problemático. A oratória e a retórica foram ocupando um espaço secundário em meus interesses como estudante.

Lembro-me de que, por conta dessa formação calcada na transmissão histórica, era tomado por uma profunda impotência. Meus colegas de curso, estudantes como eu, não entendiam muito bem o motivo. A história da filosofia parecia tão rica em suas vertentes e temas, por que questioná-la? Talvez a minha curta experiência como professor me ensinara a não tratar esse objetivo como a única forma de se relacionar com a filosofia escolar. Poderiam existir outras possibilidades, mas como estudante do curso de filosofia, ambiente de formação para professores, eu não encontrava qualquer debate acerca delas.

O desconforto da sala de aula possibilitou-me a percepção de que eu também já não ocupava o mesmo lugar da maioria de meus colegas, como estudantes do curso. A minha escolha encaminhara-se para outro rumo. De maneira adversa da maioria deles, optei pela licenciatura. Agora eu era um professor, escolha infame, de um estudante infame. Esta decisão me provocava

\footnotetext{
${ }^{6}$ Não pretendo entrar em quaisquer questões metodológicas acerca da História como saber. Mas não posso deixar de reiterar que o contato com Hélio Rebello Cardoso Júnior (2001), co-orientador de minha pesquisa de Mestrado, alertou-me para uma ausência da reflexão teórica acerca dos ardis da "história", nas disciplinas de "história da filosofia". Muito embora o regimento geral dos cursos de Filosofia nas Universidades Brasileiras seja compostos por disciplinas intituladas "História da Filosofia", nelas pouco ou nada se reflete acerca das especificidades em História. Em minha formação, o trabalho do historiador da filosofia não procurou pensar as especificidades dos arquivos, bem como a relação entre narrativa, texto e contexto. Confere, assim, uma caracterização puramente narrativa e conceitual interna ao texto filosófico, abonando-se do campo "História" como um amparo de poder.
}

Filosofia e Educação [RFE] - Volume 9, Número 2 - Campinas, SP Junho-Setembro de 2017 - ISSN 1984-9605 - p. 23-47 
uma ausência, mas também uma estranha força. Se, de um lado, a sala de aula tornava-se uma decepção, por outro, também me marcara profundamente, coisa diferente da pesquisa conceitual realizada com a retórica. Já não me conseguia ver mais fora dessa relação. Talvez nunca estivera. E agora eu precisava (re) pensá-la.

A prática como professor em um espaço heterogêneo ${ }^{7}$, a maneira como era o CAUM, permitiu que uma série de suspeitas entre a filosofia e o seu ensino desabrochasse em mim. Questões tanto atinentes à transmissão do conteúdo e do método em filosofia, quanto a sua natureza, se comparada à escolarização das demais disciplinas ou ainda à função política a que o ofício docente alude. Tais perguntas somaram-se à impressão de que as práticas universitárias com a filosofia eram igualmente problemáticas. Existia uma "História da Filosofia", que não era história, tampouco filosofia. Uma "Ética" que, de revés, era histórica.

Contudo, e mais decisivamente, pude notar que havia uma intensa dissonância entre dois lugares: o discurso da formação universitária em relação à prática escolar na educação média. A formação do licenciado era uma espécie de apêndice da formação pretensamente rígida do bacharel. A figura do professor parecia secundarizada, se comparada à do pesquisador. E esse escalonamento começou a me incomodar profundamente. A minha iniciação à filosofia não foi de ordem teórica e conceitual, mas nessa relação de desassossego defronte da formação recebida.

Posso exemplificar uma série de questões que (me e se) encontraram à época: Seria eu alguém a "explicar textos" da cultura filosófica para estudantes que, diferentemente de mim, não escolheram uma graduação de filosofia como curso? E que não pretendem existir enquanto leitores ou historiadores

\footnotetext{
${ }^{7}$ Um cursinho pré-vestibular apresenta-se como um empecilho para pensar mais livremente a filosofia, devido a sua pragmática instrumental, porém o CAUM viabilizou a não exclusão de possibilidades. Este espaço congrega estudantes de diferentes faixas etárias, graus de escolarização e com interesses muito próprios. Uns desejam apenas complementar a formação, outros procuram o ingresso na Universidade ou a preparação para concursos públicos. O elemento comum que os liga é a condição socioeconômica comprovadamente baixa, requisito para ingressar no Programa de Extensão. A heterogeneidade desse espaço possibilitou um trabalho formativo com a filosofia. Pude (re) criar rodas de conversas e atividades mais livremente, sem finalidade, nesse nível de ensino.
} 
"profissionais" da filosofia? E que "profissionais" eram estes que nunca me proporcionaram sequer uma reflexão acerca dos canteiros teóricos e metodológicos da história? Este parecia um ofício desgraçado! Em essência e muito vagarosamente, iniciei um processo de pensar diferentemente do que correntemente se pensava em minha formação de graduando. E isso, com o tempo, (me) incomodou.

O ensino de filosofia tornou-se um problema para mim. Então, quis também formalizá-lo como pesquisa de iniciação científica. Lembro que aliava a minha função de professor bolsista a uma pesquisa informal de retórica. A minha primeira motivação foi sugerir ao orientador dessa investigação a tomada do ensino de filosofia como objeto. Para a minha surpresa, além de ele não entender a minha motivação, considerou que isso não se configurava como uma temática eminentemente filosófica.

Confesso que fiquei sem compreender quais critérios legitimavam a "retórica" como um campo sumariamente filosófico, em descrédito de outro cujo nome remetia à própria filosofia, como o "ensino de filosofia". Este segundo parecia indigno de ser pensado. Eu era um tímido graduando de filosofia (há muitos deles!) e não me sentia competente para questionar quaisquer juízos de área. Mas, tampouco aceitei de bom grado a afirmação há muita ousadia nos tímidos graduandos, mesmo quando em silêncio.

Abandonei a retórica. A segunda motivação foi procurar entre os docentes do Departamento de Filosofia da Unesp de Marília qual deles poderia me auxiliar em uma iniciação científica, que tivesse como objeto a filosofia e o seu ensino. A minha surpresa foi perceber que sequer um deles se dedicava à temática em suas pesquisas. Era ingênuo, confesso, mas não pude deixar de olhar com certo estranhamento os vários professores de filosofia que não se dedicavam a pensar o seu próprio ofício.

Também notei que as pesquisas em filosofia na universidade era um lugar para especialistas. Não existindo especialistas de filosofia em ensino de filosofia, ele não seria pesquisado entre os estudantes de filosofia. O resultado de minha procura foi que esses mesmos docentes indicaram-me a área da Pedagogia, assim se referiam, pois as questões do ensino da filosofia eram ali

Filosofia e Educação [RFE] - Volume 9, Número 2 - Campinas, SP Junho-Setembro de 2017 - ISSN 1984-9605 - p. 23-47 
investigadas. Ao menos um pedagogo haveria de pensar o ofício do professor de filosofia; tranquilizei-me.

Naquele momento - e certo de que entre os pedagogos encontraria as respostas sobre o que e como ensinar - tomei conhecimento do Grupo de Estudos e Pesquisa em Educação e Filosofia (GEPEF) ${ }^{8}$. Mais surpreso do que constatar que o ensino de filosofia não era um tema filosófico e os professores de filosofia não produziam pesquisas na área, foi perceber que os pedagogos não me ofereceriam as soluções pretendidas sobre o que e como ensinar. Contudo, e mais decisivamente, mostraram outros modos de refletir as questões que trazia comigo, indicando também outra compreensão das pesquisas em Filosofia.

Em geral, o Gepef possibilitou-me um processo de pensar filosoficamente a educação em seus mais amplos aspectos. Em específico, mostrou-me que as questões do ensino de filosofia poderia também ser trabalhada filosoficamente. Essa maneira de conceber a filosofia despertoume para o fato de que uma pesquisa na área não se reduzia a um saber fechado sobre si mesmo. Poderia, enfim, pensá-la de outros modos.

Vale uma digressão. Ainda iniciante na área acadêmica, a minha concepção de um problema a ser investigado filosoficamente formalizava-se nas seguintes perguntas, tendo em vista as práticas universitárias recebidas: Sobre quem pesquisarei? Em qual conceito de determinado filósofo quero ser especialista? Por outro lado, tais perguntas tornaram-se restritas para mim, que já iniciara na docência e não encontrara esse campo contemplado nas pesquisas acadêmicas em Filosofia.

De forma contínua, o Gepef propiciou que transmudasse também esse modo restrito de compreender uma investigação. Comecei a me questionar se uma iniciação filosófica e científica deveria ser feita, necessariamente, a partir de algum filósofo canônico, bem como sobre os seus conceitos ${ }^{9}$. E mais, pude

\footnotetext{
8 O primeiro tem por lideranças Pedro Angelo Pagni e Divino José da Silva. Maiores informações sobre o GEPEF na página: http://www.marilia.unesp.br/\#!/pesquisa/grupos-depesquisa/gepef/historico/

9 Tive o privilégio do contato com Gonçalo Armijos Palácios (UFG), quando da sua participação em uma roda de conversa intitulada Guaraná Filosófico, realizado pelo ENFILO
}

Filosofia e Educação [RFE] - Volume 9, Número 2 - Campinas, SP Junho-Setembro de 2017 - ISSN 1984-9605 - p. 23-47 
compreender que a relação entre o ensino e a filosofia trazia especificidades que estavam para além do campo pedagógico.

Criamos, meses depois, um espaço para estudar o ensino e a filosofia, que intitulamos Enfilo ${ }^{10}$, subgrupo do GEPEF, a fim de pensar tais nuances. De maneira paradoxal, enquanto os professores do Departamento de Filosofia relegavam o seu modo de ensino à transmissão do sistema de pensamento de determinado autor canônico da tradição filosófica, encontrei, entre os professores oriundos dos Departamentos ligados à Educação, potencialidades para problematizar filosoficamente esse nível de ensino e aprendizado. Fui percebendo que o modo pedagógico de tratar as relações entre o ensino e o aprendizado da filosofia era apenas uma das formas possíveis. E o nosso modo era diferente desse.

Remeto um exemplo do trato filosófico na problematização dessa relação com Alejandro Cerletti (2009), um dos estudos feitos pelo Enfilo. Esse autor indica que, não sendo a filosofia um saber cuja identificação é consensual, a tarefa de ensinar promoverá no professor uma série de decisões subjetivas a serem tomadas, para além das diretrizes sobre o que e como ensinar. Perguntas tais como "que é e por que ensinar filosofia?", e ainda "se a filosofia se ensina, de quais modos seria possível?", estão imanentes ao seu ofício de dar aulas. Em suma, tais questões partem da necessidade de definição estatutária sobre esse saber, que efetivamente se responde como reflexão filosófica.

O problema é que quaisquer de meus amigos estudantes na filosofia tinham pouco acesso a essa reflexão. A sua importância, no entanto, justificase tanto para o licenciado, como para o bacharel. Da parte do primeiro, para não reproduzir as mesmas práticas de explicação exegética de texto a partir de uma história cronológica da filosofia para estudantes que não pretendem se profissionalizar na filosofia, como é o caso dos do nível médio. Da parte do

em parceria com o Centro Acadêmico "Nove de Novembro", da Unesp de Marília. Essa oportunidade propiciou que eu formulasse teoricamente a minha insatisfação com os modos de pesquisar a filosofia no Brasil. Demarco três de suas leituras, por ordem: PALACIOS, (2004, 2008).

${ }^{10}$ Grupo coordenado pelos docentes: Rodrigo Pelloso Gelamo e Vandeí Pinto da Silva. 
bacharel, pois a sua formação na pesquisa não inviabiliza o ofício docente no grau universitário. Penso que a ausência da reflexão filosófica acerca das especificidades desse ensino reverbera, invariavelmente, na má formação do professor de filosofia em ambos os níveis. Como sequência da presente narrativa, pretendo encontrar certas raízes históricas sobre a configuração acadêmica brasileira no propósito de melhor fundamentar a questão.

\section{Da restrição de pensamento na academia brasileira}

Narrada parte de minha trajetória de formação como estudante e como professor em formação dentro de um curso de filosofia reconhecidamente tradicional no Brasil, lugar em que constato a degeneração da produção de pensamento sobre a formação docente por parte do Departamento de Filosofia, entendo que a contemporaneidade que experimentei é reflexo de um processo histórico de descaso com o ensino de filosofia no país. Para verificar a hipótese trazida nesse espaço, detalharei os resultados a que cheguei em meu percurso investigativo tomando como centro as pesquisas já concluídas (PERENCINI e GELAMO, 2011; PERENCINI, 2013; 2015).

Da peculiaridade em se tratar o ensino de filosofia ao modo filosófico, inicio uma pesquisa na área, com vistas à produção bibliográfica brasileira. Em março de 2010, sob a supervisão de Rodrigo Gelamo, fui bolsista PIBIC/CNPq (Edital 2010/11 - processo 145202/2010-0) da investigação que trouxe por título $O$ "lugar" do conhecimento e da experiência no aprendizado da filosofia $(2011)^{11}$. Nela procuro analisar as produções sobre o ensino de filosofia em 16 periódicos $^{12}$, especializados em Filosofia; Educação; Educação

\footnotetext{
${ }^{11}$ Acresce dizer que essa pesquisa partiu de problemas enunciados por Gelamo (2009), em seu livro $O$ ensino da filosofia no limiar da contemporaneidade, que objetiva desenvolver uma série de questões sobre a sua prática docente, materializadas em um problema central: o que faz o filósofo quando uma de suas tarefas na contemporaneidade é ser professor de Filosofia?

${ }^{12}$ Dos 16 periódicos analisados, os de filosofia são: Trans/Form/Ação - UNESP, Discurso USP, Revista Brasileira de Filosofia - Instituto brasileiro de Filosofia, Kriterion - UFMG, Síntese - Faculdade Jesuíta de Filosofia e Teologia e Manuscrito - CLE Unicamp. Em educação: Educação e Pesquisa - USP, Educação e Realidade - UFRGS, Educação e Sociedade - Unicamp, Pro-posições - Unicamp, Revista Brasileira de Educação - ANPED, Caderno Cedes - Unicamp, Revista da Faculdade de Educação - USP, Educação em Revista
}

Filosofia e Educação [RFE] - Volume 9, Número 2 - Campinas, SP Junho-Setembro de 2017 - ISSN 1984-9605 - p. 23-47 
e Filosofia, que tiveram circulação a partir de 1934, ano da criação do curso de Filosofia na Universidade de São Paulo (USP), até o ano de 2008, com a aprovação da Lei 11.684/2008, que previa a obrigatoriedade da disciplina Filosofia para toda a educação de nível médio no país. O objetivo geral da análise foi conferir como se articulavam as noções de "conhecimento" e de "experiência" no aprendizado da filosofia.

Dessa pesquisa, verifiquei que o entendimento do ensino de filosofia esteve amplamente embasado em um modo de transmitir um conteúdo da tradição filosófica e no melhor método para fazê-lo, o que restringiu a possibilidade de pensar esse nível de aprendizado como uma experiência de pensamento. Além disso e sobretudo, pude notar que a ausência de uma reflexão sobre a filosofia e o seu ensino não era tributária apenas do Departamento de Filosofia da Unesp de Marília, mas parecia uma tendência histórica inerente a formação universitária brasileira.

Constatei a escassa produção sobre o ensino de filosofia por parte dos pesquisadores brasileiros à medida que nem um por cento dos artigos e/ou textos analisados nos 16 periódicos dedicou-se a discutir a temática em questão. Da revisão dos mais relevantes periódicos de Filosofia, de Educação e de Educação e Filosofia em circulação no Brasil, que totalizaram 9242 artigos e/ou textos revisitados, apenas $64-0,69 \%$ da produção geral - traziam por tema o ensino de filosofia com seus diferentes enfoques e deste número geral, apenas $40-0.43 \%$ da produção geral - tratavam-no com vistas às problemáticas brasileiras. A suspeita percebida, enquanto professor de filosofia, de que o discurso universitário e a prática escolar na educação média eram dissonantes, ganhou corpo nessa atividade de pesquisa, tanto pelo diagnóstico da restrição temática, como pela escassa produção sobre o ensino de filosofia nos diferentes níveis escolares.

Vale mencionar que este trabalho possibilitou um primeiro contato com documentos, lugar estrangeiro para um graduando em filosofia. A procura foi extenuante, entremeada por seriados empoeirados e deixados nos cantos

- UFMG e Revista de Pedagogia da USP. Por fim, o de educação e filosofia: Educação e Filosofia - UFU.

Filosofia e Educação [RFE] - Volume 9, Número 2 - Campinas, SP Junho-Setembro de 2017 - ISSN 1984-9605 - p. 23-47 
das bibliotecas. Ao cabo das 16 revistas, revisei quase dez mil documentos sobre educação e filosofia, na tentativa, quase inexistente, de encontrar vestígios sobre uma produção do ensino de filosofia. Pude compreender que a atividade de arquivista, que se empoeira na procura de indícios, era uma compreensão do testemunho do passado. Tendo encontrado poucos documentos nos periódicos anteriormente verificados, decidimos ampliar o número de análise. Iniciávamos a responsabilidade de resgatar uma memória sobre a temática do ensino de filosofia devido a sua percepção de ausência no presente.

Em outra pesquisa intitulada $O$ Ensino de Filosofia no Brasil: A recepção e o seu debate nos periódicos brasileiros (2013), sob o fomento da FAPESP [Processo 2011/21785-0. Vigência de 01/03/2012 a 31/12/2012], na modalidade Iniciação Científica, investiguei qual a recepção do debate sobre o ensino de Filosofia em mais 10 periódicos brasileiros ${ }^{13}$. As publicações com o início de circulação nos decênios de 1930, 1940 e 1950 foram enfatizadas, tendo elas continuado posteriormente ou não. Houve nisso a pretensão de melhor compreendermos como foi pensado o ensino de filosofia no momento da criação e consolidação das Universidades e também dos cursos de filosofia no Brasil.

A nova revisão bibliográfica nos periódicos em vigência no período reiteraram a escassez de produção sobre a temática "ensino de filosofia" no país. Vale a nota de que nem $0.30 \%$ de sua produção geral se dedicou ao referido assunto. Se tomarmos esse conjunto de textos como base para a investigação quantitativa, podemos concluir que o pensamento sobre o ensino de Filosofia no Brasil foi escasso, além de tardio, já que o ensaio A difusão da

\footnotetext{
${ }^{13}$ Os dez periódicos são divididos entre as áreas de Educação e de Filosofia. São da área de Educação: Revista de Educação (São Paulo: Secretaria da Educação do Estado de São Paulo, 1927 a 1961); Boletim de Educação Pública (Distrito Federal - RJ: Secretaria Geral de Educação e Cultura, 1930 - 58); Formação: Revista Brasileira de Educação (Rio de Janeiro: Imprensa Nacional, 1938 - 54); Educação (Rio de Janeiro: Associação Brasileira de Educação, 1939 - 1967); Revista do Ensino (Porto Alegre: Secretaria de Educação e Cultura do RS, 1951 - 1974). Os periódicos em Filosofia são: Anais da Sociedade Brasileira de Filosofia (Rio de Janeiro: A Sociedade, 1939 - 1955); Organon (Porto Alegre: Faculdade de Filosofia - UFRGS, 1956 - 69); Doxa (Pernambuco: Revista oficial do Departamento de Cultura Acadêmica da Faculdade de Filosofia de Pernambuco. 1952 - ?); Verbum (Rio de Janeiro: PUC, 1944 - 1979); Veritas (Porto Alegre: PUC, 1956 -.)
} 
Filosofia, de autoria de A. S. Oliveira Júnior (1939/40), primeiro texto a tratar da temática, só aparece em 1939, portanto cinco anos depois da criação do curso de Filosofia na Universidade de São Paulo (USP), marco institucional no país. O segundo texto que encontramos só aparece 10 anos depois. Tratase do artigo A Filosofia na Escola Moderna, de Irene da Silva Mello Carvalho (1949). Vale também mencionar que não houve nenhum número que se dedicou exclusivamente ao ensino de filosofia a partir da análise em periódicos de educação e de filosofia que a presente investigação nos ofereceu.

Esta pesquisa foi fundamental para constatar a suspeita enunciada por Gelamo (2009) de que a discussão sobre o ensino de Filosofia no Brasil foi perspectivada, em grande medida, sob três diferentes enfoques: (1) do entendimento da importância do ensino da filosofia para a sociedade, para a cultura e para a formação crítica do homem; (2) da reflexão sobre os temas e conteúdos a serem ensinados e sobre o currículo; (3) da busca do entendimento metodológico do ensino da filosofia. Os documentos mostraram que a academia brasileira restringiu o pensamento acerca do ensino de filosofia tanto pela sua produção quantitativamente irrisória, como pela restrição qualitativa no debate.

O curso investigativo de minha iniciação científica foi fundamental para ensejar outra percepção de ausência. Por um lado, os documentos contemporâneos sobre o ensino de filosofia remetem sobremaneira a uma defesa filosófica de seu debate. Por outro, pouco se referem a sua produção histórica no país. Notar essa ambiguidade foi fundamental para iniciar uma pesquisa de maior fôlego, em âmbito de mestrado.

De certa maneira, a literatura contemporânea sobre a questão tem se dedicado largamente a fundamentar o ensino de filosofia como uma problemática filosófica, campo que merece ser investigado pelo filósofo de ofício, principalmente com o advento da filosofia na educação média brasileira, uma vez que ora buscam a justificação problemática na tradição 
clássica em Kant e $\mathrm{Hegel}^{14}$, ora no questionamento da natureza filosófica em face do seu ensino, que pretende tornar o ensino de filosofia um problema filosófico ${ }^{15}$. Ora compreendendo o aprendizado dessa transmissão entremeada a uma experiência filosófica ${ }^{16}$. Ou ainda, refletindo criticamente sobre os aspectos mais técnicos desse nível de ensino, como o aporte ao material didático e à leitura do texto filosófico ${ }^{17}$.

Por outro lado, percebi no resgate dos arquivos dentro dos periódicos a ausência de considerações históricas para melhor fundamentar o debate filosófico sobre a questão no Brasil. Ao analisar as produções teóricas a partir da década de 2000, decênio em que se acentua a importância da discussão sobre o ensino da filosofia no país, constatei a ausência de referências a quem desenvolveu o seu discurso em decênios anteriores. Encontrei, ainda, apenas um artigo que buscou mapear o ensino de filosofia no Brasil, uma publicação do ano de 2004 intitulada $O$ ensino de filosofia no Brasil: uma mapa das condições atuais $^{18}$, na qual, a pedido da UNESCO, vários autores buscaram diagnosticar as condições atuais para o seu desenvolvimento nas diversas regiões brasileiras. Mas mesmo essa publicação não procurou contextualizar historicamente o assunto.

Diferentemente disso, Moraes Filho (1959) ${ }^{19}$ e Paim $(1970)^{20}$ procuraram uma compreensão histórica do ensino de filosofia desde o período colonial no Brasil, porém ainda não encontramos uma reconstituição de memória mais apurada entre a década de 1930 a $1968^{21}$, que tematizasse

\footnotetext{
14 Menção específica ao debate: Ensina-se a filosofia (e sua história) e/ou aprende-se a filosofar? De certo modo, artigos em especial focam o problema mencionado: GELAMO (2008), HORN (s.d.), NOVELLI (2005), RAMOS (2007).

15 Conferir CABRERA e CERLETTI (2001), CERLETTI (2008), MURCHO (2008), GELAMO (2008a, 2008b).

${ }^{16}$ Inspirados na Filosofia da Diferença, ressoa o debate entre o ensino de filosofia e a experiência filosófica, de um modo ou de outro, nos seguintes artigos: GALLINA (2004), DANELON (2004), ASPIS (2004), GELAMO (2006), GALLO (2008), KOHAN (2008).

17 São exemplos destes os artigos: ALVES (2003), FABBRINI (2005).

${ }^{18}$ Conferir: FÁVERO et al (2004).

${ }^{19}$ Conferir: FILHO (1959).

${ }^{20}$ PAIM (1970).

${ }^{21}$ Beda Kruse (1954), com a publicação de o Desenvolvimento e Importância das Faculdades de Filosofia no Plano Educacional Brasileiro de 1936 a 1950 aproxima-se do nosso propósito, mas o seu resgate histórico não tem o enfoque preciso no ensino de filosofia brasileiro. Atém-se ao desenvolvimento das Faculdades de Filosofia no país.
}

Filosofia e Educação [RFE] - Volume 9, Número 2 - Campinas, SP Junho-Setembro de 2017 - ISSN 1984-9605 - p. 23-47 
principalmente o nível universitário, responsável pela formação do professor e pesquisador em filosofia no país. Dito isso, podemos considerar que não houve apenas um pensamento escasso sobre o assunto por parte da academia brasileira, mas também a própria literatura contemporânea sobre o ensino de filosofia parece se referir minimamente a essa produção anterior.

Evidentemente, não nego que a contemporaneidade tenha produzido investigações que retomem certa história sobre a temática pesquisada, mas demarco que a busca por um corpus teórico pouco se evidenciava no campo de pesquisas acerca do ensino de filosofia no país. No propósito de pensar um “estado da questão" sobre o ensino de filosofia é que se constituiu a nossa última pesquisa concluída, nomeada $O$ ensino de filosofia no Brasil: A sua formação discursiva no contexto universitário de 1930 a 1968 (2015) [FAPESP Processo: 2012/21672-4] ${ }^{22}$, onde procuro fazer um resgate da formação discursiva ${ }^{23}$ do debate acadêmico do ensino de filosofia nos anos formadores da Universidade brasileira.

Vasculhamos $^{24}$ os arquivos sobre o ensino de filosofia universitário em cerca de 41 periódicos de filosofia e de educação circulados no Brasil, sendo 18 deles da área "filosofia" e 23 da área "educação", que estiveram em circulação desde a década de 1930 - data em que teve início a maior divulgação da filosofia em território brasileiro, precipuamente com a criação da Faculdade de Filosofia da Universidade de São Paulo (USP) em 1934 - até 1968, ano em que ocorreu a Reforma Universitária ${ }^{25}$ no país, fixando uma série de normas e diretrizes de organização para o seu ensino superior.

\footnotetext{
${ }^{22}$ Pesquisa a ser publicada em livro após concorrer ao Edital EDITAL No. 06/2016 - PROPG Programa de publicações Coleção PROPG Digital - Selo "Cultura Acadêmica". Conferir o resultado online: file:///C:/Users/Tiago/Downloads/resultado-e-book-cad-propg-edital-062016\%20(2).pdf.

${ }^{23}$ A ideia de "formação discursiva" encontra-se dentro do campo arqueológico de Michel Foucault (2008), mas como não é este o propósito desse artigo, não me deterei ao conceito.

${ }^{24}$ Esse percurso de catalogar arquivos soma-se a outras investigações desenvolvidas pelo doutoramento de GELAMO (2009), que se desmembrou nas investigações de SANABRIA (2014), PERENCINI (2015) e SALVADORI (2012).

${ }^{25}$ Referência específica à outorga da Lei n ${ }^{\circ} 5.540$, de 28/11/68. Como lembra Fávero(2006, p. 33), "Entre as medidas propostas pela Reforma, com o intuito de aumentar a eficiência e a produtividade da universidade, sobressaem: o sistema departamental, o vestibular unificado, o ciclo básico, o sistema de créditos e a matrícula por disciplina, bem como a carreira do magistério e a pós-graduação".
}

\begin{tabular}{|c|c|}
\hline $\begin{array}{c}\text { Filosofia e Educação [RFE] - Volume 9, Número 2 - Campinas, SP } \\
\text { Junho-Setembro de } 2017 \text { - ISSN 1984-9605 - p. 23-47 }\end{array}$ \\
\hline
\end{tabular}


Nessa pesquisa, pude concretizar o mapeamento do debate acerca do ensino de filosofia no Brasil pelos discursos universitários entre os anos de 1930 e 1968, tarefa iniciada desde a minha iniciação científica. De um ponto de vista quantitativo, contabilizei aproximadamente a presença de 11.600 textos em 1240 edições e procuro os vestígios da produção brasileira do ensino de filosofia. Desse material, localizo $41 \operatorname{textos}^{26}$ que possibilitaram elementos para pensá-lo, o que configura apenas 0.35 por cento da produção total revisada. Toda a sistematização numérica da pesquisa pode ser encontrada em Perencini (2015).

A sistematização das bases de dados para as pesquisas futuras sobre o ensino de filosofia no Brasil parece ainda escassa, mas de fundamental importância para o fortalecimento desse campo de saber ${ }^{27}$. Entendo que a minha contribuição se configura na materialidade dos periódicos. Da parte dessa finalidade, há uma consideração a ser emitida.

Muito embora tenham sido encontrados textos que se relacionem ao ensino de filosofia no Brasil tomando como recorte temporal os anos iniciais da universidade brasileira, não é possível afirmar que existiu uma produção de pensamento que tomasse a questão como campo de saber. Ainda que encontrasse 41 textos para análise, tais arquivos podem ser também considerados como relatórios, divulgação de eventos na área, resenhas, etc e que não tomam a temática do ensino de filosofia como reflexão filosófica ou central. Partindo dessa premissa, é possível afirmar que o tema ensino de filosofia foi ausente como campo de pensamento e pesquisa nos anos

\footnotetext{
${ }^{26}$ A dimensão do texto não se restringe a artigos ou a textos de produções teóricas. Há, entre tais arquivos, relatórios, divulgação de eventos na área, resenhas, etc. Desde já quero desfazer a impressão de que a produção acerca do ensino de filosofia no período foi considerável. Noto, ao invés disso, uma ausência profunda em sua participação como tema de pensamento/pesquisa nos anos formadores da universidade brasileira.

${ }^{27}$ Pude perceber claramente a relação entre a escassez e a necessidade dessa sistematização de pensamento quando da minha participação como comunicador no Grupo de Trabalho Filosofar e ensinar a filosofar do XVI Encontro Nacional da Associação Nacional de PósGraduação em Filosofia no Brasil (ANPOF). Dado que esse evento reúne os pesquisadores que se têm dedicado mais pormenorizadamente a tratar o ensino de filosofia no Brasil, percebi um grande interesse pela sistematização das bases de dados no período tratado, mas também um grande desconhecimento do que foi produzido.
}

Filosofia e Educação [RFE] - Volume 9, Número 2 - Campinas, SP Junho-Setembro de 2017 - ISSN 1984-9605 - p. 23-47 
formadores da universidade brasileira tomando as áreas de Educação e de Filosofia.

Ao mesmo tempo em que foi de suma importância recolher vestígios em materiais de diferentes naturezas, que remeteram indiretamente ao ensino de filosofia no período tratado, também averiguo que uma ínfima quantidade entre eles se dedicou a pensar esse assunto como campo de saber ${ }^{28}$. Ora, em lugar de um debate efetivo entre autores e instituições em quase três décadas de insurgência da Universidade brasileira, o que encontro são dispersões de textos que me levaram a conceber que a filosofia já se constituía como disciplina escolar em diferentes graus. É possível concluir que, entre os anos 1930 e 1968, tomando o periódico como materialidade de pesquisa, não houve um saber que se possa nomear "ensino de filosofia".

A pesquisa efetuada foi de fundamental importância para clarificar por quais caminhos se iniciou este debate na formação do professor e do pesquisador em filosofia no país. Nesse sentido, entendo que a análise de periódicos entre 1930 e 1968 foi também importante na contribuição das pesquisas efetuadas por Gelamo (2009), que, já na sua tese de doutoramento, notou a baixa produção especializada acerca do ensino de filosofia. Pude contribuir para constatar a existência de uma irrisória produção discursiva até 1968, o que compactua na hipótese de que "ensino de filosofia" não parece se inscrever como saber nos anos formadores do discurso filosófico e pedagógico no país.

\section{Consideração Final}

A exposição acima foi fundamental para tencionar o problema levantado nesse artigo, que enfoca de que maneira a ausência histórica da produção de pensamento sobre a formação docente se faz sentir na tradição universitária filosófica contemporânea no Brasil. Procurei mostrar como se deu essa restrição tomando a produção acadêmica sobre o ensino de filosofia dentro dos

${ }^{28}$ Encontrei uma reflexão mais apurada em raríssimos arquivos dentre os sistematizados Refiro-me aos textos específicos: VELLOSO (1951) CORBISIER (1952), MAUGUÉ (1955), VITA (1956), MORAES FILHO (1959).

Filosofia e Educação [RFE] - Volume 9, Número 2 - Campinas, SP Junho-Setembro de 2017 - ISSN 1984-9605 - p. 23-47 
periódicos de educação e de filosofia para análise de um ponto de vista histórico, constatando que o ensino de filosofia não se configurou como uma temática relevante dentro da constituição universitária que envolvia os campos da pedagogia e da filosofia no Brasil.

Entendo que essa restrição também acarretou a ausência de um pensamento efetivo acerca da formação docente em filosofia no país. Vale a nota de que a nossa revisão bibliográfica teve como propósito, primeiramente, a procura pelo tema "ensino de filosofia universitário", mas ao perceber a verdadeira ausência dessa prática de pensamento, fomos obrigados a estender o objeto para o "ensino de filosofia" em linhas gerais e procurar pelos restos envolvendo o campo de práticas que alicerçou a formação docente no país.

Tal descaso por parte da comunidade acadêmica tem sido sentido contemporaneamente, como se pode perceber na primeira parte desse artigo, espaço em que testemunho a minha experiência de (de) formação universitária. Os acontecimentos da vida, somados à prática da investigação formal, mostraram-me que a filosofia acadêmica parece ter privilegiado a pesquisa aos moldes da erudição europeia (SANABRIA DE ALELUIA, 2014) para a formação do bacharel, o que reduziu as práticas de formação do professor em filosofia no Brasil à transmissão das especificidades técnicas que envolvem o trabalho do pesquisador, restrita por consequência ao debate didático e pedagógico sobre o ensino de filosofia, atinente a importância, ao conteúdo e ao método para sua transmissão enquanto disciplina em uma instituição escolar de educação média (GELAMO, 2009; PERENCINI e GELAMO, 2011; PERENCINI, 2013, 2015).

Tais enfoques tendem a restringir o exercício do filosofar e parecem revestir a filosofia com uma dimensão científica, munindo exclusivamente o estudante de filosofia de técnicas ditas rigorosas sobre a leitura e a escrita de textos considerados clássicos pela tradição. Ao menos foi esta a maneira como ocorreu a graduação em filosofia na qual fui formado como docente.

Por outro lado, tomando a minha trajetória na Universidade como arquivo vivo para testemunho no presente, percebi que me formei apesar do modo como eram concebidas as práticas universitárias em filosofia nessa

Filosofia e Educação [RFE] - Volume 9, Número 2 - Campinas, SP Junho-Setembro de 2017 - ISSN 1984-9605 - p. 23-47 
instituição. Posso afirmar que a densidade formativa em meu percurso ocorreu a partir de meu início prematuro na experimentação como professor de filosofia em um lugar heterogêneo, levando em conta os laços afetivos que me uniam nos eventos e grupos de estudos que escapavam às diretrizes do Departamento de Filosofia e também na esfera de atuação política a que me envolvi durante anos. Este percurso formativo foi possibilitado pelos acontecimentos da vida em seu tempo próprio e que pouco ou nada ingressou nas práticas institucionais.

A experiência de esgotamento de minha geração sobre o tipo de formação universitária oferecida em filosofia, aliada a percepção de certo saturamento na produção discursiva por parte da tradição acadêmica dedicada a pensar atualmente o ensino de filosofia no país (GALLO, 2016) tem possibilitado o seguimento de minhas pesquisas na tentativa de conferir visibilidade à dimensão ética, afetiva e subjetiva do professor de filosofia. Esta tarefa transcende o próprio ensino de filosofia e a instituição (universitária e escolar) e procura empreender as práticas de formação a partir de uma educação filosófica no qual o aprendizado da filosofia representa um exercício de experimentação, transformação e postura em face do presente e da vida (PAGNI, 2016).

\section{Referências}

ALVES, A. J. L. Os PCN e o Ensino de Filosofia. Educação e Filosofia, Uberlândia, v.17, n.34, p. 101-115, 2003.

ASPIS, R. P. L. O professor de Filosofia: O ensino de Filosofia no ensino médio como experiência filosófica. Caderno Cedes, Campinas, v.24, n.64, p. 305-320, 2004.

BRASIL. Decreto de lei n. 11.684, de 02 de junho de 2008. Disponível em: <http://www.planalto.gov.br/ccivil_03/_Ato2007-2010/2008/Lei/

L11684.htm>. Acesso em: 1 jun. 2014.

Parecer CNE/CES 492/2001, 03 de abril de 2001. Trata o presente de diversos processos acerca das Diretrizes Curriculares Nacionais dos cursos de Filosofia, História, Geografia, Serviço Social, Comunicação Social, Ciências 
Sociais, Letras, Biblioteconomia, Arquivologia e Museologia remetidas pela SESu/MEC para apreciação da CES/CNE. In: Diretrizes Curriculares Nacionais dos cursos de Filosofia, História, Geografia, Serviço Social, Comunicação Social, Ciências Sociais, Letras, Biblioteconomia, Arquivologia e Museologia. Brasília, 2001. p.1-38.

CABRERA, M. CERLETTI, A. Política de la enseñanza de la Filosofia. Educação e Filosofia, Uberlândia, v.15, n.30. p. 103-116, 2001.

CARDOSO JÚNIOR, H. R. Tramas de Clio: convivência entre filosofia e história. Curitiba: Tetravento, 2001.

CERLETTI, A. O ensino de filosofia como problema filosófico. Trad. Ingrid Muller Xavier. Belo Horizonte: Autêntica, 2009.

- Enseñanza filosófica: Notas para La construcción de um campo problemático. Educação e Filosofia, Uberlândia, v.22, n. 44, p. 43-54, 2008.

CORBISIER, R. A introdução à filosofia como problema. Revista Brasileira de Filosofia. V. II, n. 4, p. $668-678,1952$.

DANELON, M. Para um ensino de Filosofia do caos e da força: uma leitura à luz da Filosofia nietzschiana. Caderno Cedes, Campinas v.24, n.64, p.345-358, 2004. FABBRINI, R. N. O ensino de Filosofia: a leitura e o acontecimento. Trans/Form/Ação, São Paulo, v. 28, n. 2, p. 7-27, 2005.

GALlinA, S. O ensino de filosofia e a criação de conceitos. Caderno Cedes, Campinas, v.24, n.64, p. 359-371, 2004.

GAGNEBIN, J. M. Lembrar, escrever, esquecer. São Paulo: Editora 34, 2006.

GALLO, S. Filosofia e o exercício do pensamento conceitual na educação básica. Educação e Filosofia, Uberlândia, v.22, n.44, p. 55-78, 2008.

GELAMO, R. P. O ensino de filosofia no limiar da contemporaneidade: O que faz o filósofo quando o seu ofício é ser professor de filosofia? São Paulo: Cultura Acadêmica, 2009.

Pensar sem pressupostos: condição para problematizar o ensino da filosofia. Pro-posições, Campinas, v. 19, n. 3 (57), p. 161-174, $2008 \mathrm{a}$.

. A imanência como "lugar" do ensino da filosofia. Educação e Pesquisa, São Paulo, v. 34, n. 1, 2008b.

- A questão da experiência no ensino da filosofia: um problema contemporâneo. Educação em Revista (UFMG. Impresso), v. 26, p. 382-400, 2010.

Filosofia e Educação [RFE] - Volume 9, Número 2 - Campinas, SP Junho-Setembro de 2017 - ISSN 1984-9605 - p. 23-47 
O ensino da filosofia no Brasil: um breve olhar sobre algumas das principais tendências no debate entre os anos de 1934 a 2008. Educação e Filosofia (UFU. Impresso), v. 24, p. 331-350, 2010.

- Notas sobre o problema da explicação e da experiência no ensino da Filosofia.

Educação e Pesquisa (USP. Impresso), v. 32, p. 527-538, 2010.

FÁVERO, A. A.; CEPPAS, F.; GONTIJO, P.; GALLO, S.; KOHAN, W. O. O

Ensino de Filosofia no Brasil: um mapa das condições atuais. Caderno Cedes, Campinas, v.24, n.64, p. 257-284, 2004.

FÁVERO, M. L. A. A Universidade no Brasil: das origens à Reforma Universitária de 1968. Educar, Curitiba, n. 28, p. 17-36, 2006.

FILHO, E. M. O ensino de Filosofia no Brasil. Revista Brasileira de Filosofia, São Paulo, v. 9, n. 1, p. 19-45, 1959.

A arqueologia do saber. Trad. Luiz Felipe Baeta Neves. 7.ed. Rio de Janeiro: Forense Universitária, 2008a.

GALLO, S. Governamentalidade democrática e ensino de filosofia no Brasil contemporâneo. Cadernos de pesquisa, São Paulo, v.42, n.145, p.48-65, jan.-abr., 2012.

HORN, G. B. Do ensino da filosofia a filosofia do ensino: contraposições entre Kant e Hegel. Grupo de Trabalho Filosofia da Educação n. 17.

KOHAN, W. O. Sócrates, la Filosofia y su enseñanza. Actualidad de uma invención. Educação e Filosofia, Uberlândia, v.22, n.44, p. 115-139, 2008.

KRUSE, Dom Beda. A Faculdade de Filosofia, fator imprescindível de cultura: o problema da especialização. Paideia: revista da Faculdade de Filosofia, Ciências e Letras de Sorocaba, Sorocaba, v. 1, n. 1, p. 12-27, 1954.

MAUGUÉ, Jean. O ensino da filosofia e suas diretrizes. V. 7, n. 27-28, 29-30. Belo Horizonte: Kriterion, 1955.

MORAES FILHO, Evaristo de. O ensino de Filosofia no Brasil. Revista Brasileira de Filosofia, São Paulo, V. 9, n. 1, p. 18 - 45, 1959.

MURCHO, D. A natureza da Filosofia e seu ensino. Educaşão e Filosofia, Uberlândia, v. 22, n. 44. p.79-99, 2008.

NOVELLI, P. G. A. O ensino de Filosofia segundo Hegel: contribuições para a atualidade. Trans/Form/Ação, São Paulo, v. 28, no 2, p. 129-148, 2005.

Filosofia e Educação [RFE] - Volume 9, Número 2 - Campinas, SP Junho-Setembro de 2017 - ISSN 1984-9605 - p. 23-47 
PAGNI, P. Considerações sobre a educação filosófica no ensino médio e o seu sentido ético-formativo. SEVERINO, A. J.; LORIERI, M. A.; GALLO, S (orgs). O papel formativo da Filosofia. Jundiaí, Paco Editorial, 2016.

PAIM, Antônio. A filosofia no Brasil como disciplina universitária. Revista Brasileira de Filosofia, São Paulo, v. 20, n. 78, p. 208-218,1970.

PALACIOS, G. A. De como filosofar sem ser grego, estar morto ou ser gênio. Goiás: Ed. UFG, 2004.

. A. Alheio Olhar. Goiânia: Editora UFG, 2004.

- Perguntas autoritárias: a questão do método, as monografias e o filosofar. Educação e Filosofia. Uberlândia/MG. v.22, n. 44. pp. 101-114. 2008.

PERENCINI, T. B.; GELAMO, R. P. O "lugar" do conhecimento e da experiência no aprendizado da filosofia. Marília: Pibic/cnpq, 2011. 70 p.

PERENCINI, T. B. O Ensino de Filosofia no Brasil: A recepsão e o seu debate nos periódicos brasileiros. Marília: Fapesp, 2013. 177 p.

O Ensino de Filosofia no Brasil: A sua formação discursiva no contexto universitário de 1930 a 1968. 2015. 163 f. Dissertação (Mestrado) - Curso de Educação, Programa de Pós-graduação em Educação, Unesp/marília, Marília, 2015. Disponível em: <http://www.marilia.unesp.br/Home/PosGraduacao/Educacao/Dissertacoes/perecini_tb_me_mar.pdf $>$. Acesso em: 29 Ago. 2015.

RAMOS, C. A. Aprender a filosofar ou aprender a filosofia: Kant ou Hegel? Trans/Form/Ação, São Paulo, v. 30, n. 2, p. 197-217, 2007.

SALVADORI, T. T. Discussão e projeção do ensino de filosofia no Brasil através dos periódicos de filosofia. Fapesp, Iniciação 2012. Disponível em: http:// www.bv.fapesp.br/pt/pesquisador/169334/theo-tanus-salvadori/. Acesso em: 15 mai. 2017.

SANABRIA DE ALELUIA, J. R. A invenção do filósofo ilustrado. Notas arqueológicas sobre o ensino de filosofia no Brasil. São Paulo, Cultura Acadêmica, 2014.

UNIVERSIDADE DE SÃO PAULO (USP). Projeto pedagógico (De acordo com a Deliberação da CEE $\mathrm{n}^{\circ}$ 99, de 24/05/2010). Disponível em: 
http://filosofia.fflch.usp.br/departamento/projetoacademico.Acesso

em: 08/09/2016. Quinquênio 2012 - 2016.

UNIVERSIDADE ESTADUAL PAULISTA - UNESP. Faculdade de Filosofia e Ciências. Projeto Pedagógico do Curso de Filosofia. Marília, s. d. Disponível em: <http://www.marilia.unesp.br/Home/Graduacao/Filosofia/projeto.pdf>. Acesso em: 8 jun. 2014.

VELLOSO, A. V. A filosofia como matéria de ensinança. Kriterion. No 15 e 16, p. $22-52,1951$.

VITA, L. W. A filosofia e seu ensino. Revista de Pedagogia USP. São Paulo, n. 3. p. 89 a 101, 1956. 